\title{
IMPACT OF DIFFERENT LEVELS OF DISEASE ACTIVITY IN PAINFUL PROFILE AND QUALITY OF LIFE IN PEOPLE WITH RHEUMATOID ARTHRITIS
}

\author{
Selena Márcia Dubois Mendes ${ }^{\alpha}$ \\ Bárbara Liliane Lôbo Queiroz ${ }^{b}$ \\ Larissa Vieira Santana ${ }^{b}$ \\ Abrahão Fontes Baptista ${ }^{c}$ \\ Mittermayer Barreto Santiago ${ }^{d}$ \\ Kátia Nunes Sá ${ }^{\mathrm{e}}$
}

\begin{abstract}
Rheumatoid arthritis (RA) is a systemic inflammatory autoimmune disease with impact on increasing the morbidity and mortality rates. Different levels of disease activity (LDA) have been established, however, its impact on pain and quality of life have yet to be been evidenced. The aim of this study was to evaluate the relationship of different levels of disease activity on the painful profile and quality of life (QOL) of patients diagnosed with RA. This was a cross-sectional study, conducted in RA patients attending an Educational Outpatient Care Service in Salvador, Bahia, Brazil. The LDA was defined according to values of Erythrocyte Sedimentation Rate (ESR), Visual Analog Scale (VAS), and number of swollen and sore joints, according to the Disease Activity Score in 28 joints (DAS28). Types of pain were assessed using the Douleur Neuropathique en 4 questions (DN4). To evaluate QOL, the Short Form (36) Health Survey (SF-36) and Health Assessment Questionnaire (HAQ) were applied. The association between LDA, QOL and painful profile was verified using One Way-ANOVA and Bonferroni correction post-test. A high LAD was observed in $67.7 \%$ of the 96 patients

Corresponding author: katia-coordpos@bahiana.edu.br

a. MSc, Adjunct professor, Bahiana School of Medicine and Public Health and Federal University of Bahia, Salvador, Bahia, Brazil

b. Undergraduate Physiotherapy student, of Bahiana School of Medicine and Public Health. Recipient of a scientific iniciation grant from the Bahia Foundation for the Support of Research (Fapesb)

c. PhD, Adjunct professor, Bahiana School of Medicina and Public Health and Federal University of Bahia, Salvador, Bahia, Brazil

d. PhD, Rheumatologist, Adjunct professor, Bahiana School of Medicine and Public Health and Federal University of Bahia, Salvador, Bahia, Brazil

e. PhD, Adjunct professor, Bahiana School of Medicine and Public Health, Salvador, Bahia, Brazil.
\end{abstract}


evaluated in this study. Pain sensation was reported by $94.8 \%$ of participants with $40.6 \%$ reporting it as nociceptive and $80.2 \%$ as intense. It was also observed that the higher LAD found the higher was the pain intensity reported $(p=0.001)$ and lower QOL scores $(p<0.001)$. Although the LDA did not correlate with the type of pain $(p=0.611)$, it was correlated with the total score obtained in the QOL from the HAQ $(p=0.001)$. The greatest impact on QOL evaluated through the SF-36 were physical $(p<0.001)$ and functional capacity $(p<0.001)$. In conclusion, RA patients who had high LDA reported more severe pain perception and obtained the lowest scores in the assessment of quality of life.

Keywords: Rheumatoid arthritis. Level of Disease Activity. Neuropthic Pain. Nociceptive Pain. Quality of Life.

\section{INTRODUCTION}

Rheumatoid arthritis (RA) is a systemic inflammatory autoimmune disease of unknown etiology, characterized by peripheral and symmetric polyarthritis that leads to deformity and destruction of joints due to bone and cartilage erosion. Epidemiological studies estimate the prevalence of RA in $1 \%$ of the adult population, ranging from 0.4 to $1.9 \%$ worldwide. In Brazil, the prevalence of RA is 0.2 to $1 \%$.(1) This condition is be classified according to the level of disease activity (LDA) as in remission, mild, moderate or severe by the Disease Activity Score (DAS28). ${ }^{(2)}$

The main complaint of patients with RA is the presence of pain, followed by functional disability when performing daily activities. ${ }^{(3,4)}$ The pain may be nociceptive (caused by activation of nociceptors), neuropathic (resulting from alteration or damage to the nervous system) or mixed (showing both neuropathic and nociceptive components). (5) Because RA is a highly inflammatory disease, it is believed that pains arising from this disease have nociceptive characteristics, however it is not well known whether these factors are associated with neuropathic pain in this population, as they may be caused by drug use, ${ }^{6}$, 7) entrapment of peripheral nerves ${ }^{(8)}$ or maladaptive plasticity in the central nervous system. ${ }^{(9)}$

It is established that RA is a debilitating condition which imposes a significant impact on quality of life (QOL) of these patients. Factors, such as pain intensity and functional capacity, may be related to decreased $\mathrm{QOL}$ in patients diagnosed with RA. ${ }^{(10,11)}$
The association between clinical data and QOL in RA has been studied. However, the relationship of pain profile, the level of disease activity (LDA) and QOL in this population is not well described and could represent an important marker for monitoring of RA. Thus, the aim of this study was to assess the impact of different levels of disease activity in painful profile and quality of life in patients diagnosed with rheumatoid arthritis.

\section{METHODOLOGY}

This cross-sectional study was conducted with RA patients attending the Educational Outpatient Care Service of Bahia (ADAB) from the Bahiana School of Medicine and Public Health, Brotas, Salvador, Bahia, Brazil. The sample calculation based on a population of 284 patients, a standard deviation of 20 for the mean of the total score mean of QOL, difference to be detected of 8 , significance level of $5 \%$ and study power of $80 \%$, revealed a minimum sample of 77 individuals. For this calculation, we used the online calculator from the Laboratory of Epidemiology and Statistics of the University of São Paulo (USP).

The criteria for inclusion in this study considered only RA patients of both genders, aged between 18-50 years, with RA medical and clinical diagnostic confirmed through blood tests and radiological exams, according to the criteria of the American College of Rheumatology. 
Patients with cognitive impairment who were unable to complete the questionnaires were excluded.

The criteria of the Brazilian Association of Research Companies (ABEP) for social class and education categories were used to determine the socioeconomic class.

For clinical data acquisition, several validated scales and questionnaires were used: a) to determine affected areas, body map of the Disease Activity Score 28 (DAS28) was used, b) to assess the intensity of pain, the Visual Analog Scale for Pain (VAS-D) was used, to determine the type of pain, the Douleur Neuropathique en 4 questions (DN4) was used, and d) to assess the QOL, the Medical Outcomes Study 36 - Item Short-Form Health Survey (SF-36) and the Health Assessment Questionnaire (HAQ) were used. Blood samples collected were used to perform the following tests: rheumatoid factor (RF), Erythrocyte sedimentation rate (ESR), C-reactive protein (CRP) and antinuclear antibodies (ANA). The level of disease activity (LDA) was defined according to values of ESR, VAS-D and the number of swollen and sore joints (Disease Activity Score - DAS 28). The remission index was defined by the cutoff at $\leq 2.4$, low activity index was characterized by the interval between 2.5 to 3.6 , moderate activity index was considered as values from 3.7 to 5.5 , and high disease activity index was characterized by values $>5.6 .^{(12)}$ To confirm medical and clinical diagnosis, radiographic examination of both right and left wrists as well as hands were performed.

Based on previous data, the data collection followed the sequence: blood test, followed by radiological examination and application of specific questionnaires in the form of stations, with the same researcher responsible for the implementation of each specific instrument.
The level of disease activity was considered as the predictor variable and the type of pain (neuropathic, nociceptive or mixed), pain intensity and QOL scores were considered as outcome variables.

To describe the characteristics of the sample, mean and standard deviation (numerical variables) as well as proportions (categorical variables) were used. To verify the association between variables, One WayANOVA followed by Bonferroni correction post-test were performed.

All the procedures included in this research project were approved by the Ethics and Research EBMSP Committee under protocol number 014/2011. Each volunteer read and signed the Term of Free and Informed Consent and all procedures followed to determine the Decree-Law 196/96 of the CNS for human research.

\section{RESULTS}

From 102 patients diagnosed with RA attending the $A D A B, 5$ individuals were excluded from participating in the study due to incomplete data and 1 individual for presenting mild LDA. Therefore, a total of 96 patients were evaluated in the strata of moderate and high LDA. There was a predominance of females (92.7\%) and the mean age was $51.7 \pm 11.7$ years. The predominant characteristics of the population evaluated was the self-declared mixed skin color $(47.9 \%)$, social class C2 was the most frequent (38.5\%), completion of high school education (34.4\%) and $32.2 \%$ were considered overweight by the body mass index (BMI; Table 1 ). 
Table 1. Socio-demographic characteristics of the bearers of Rheumatoid Arthritis users Ambulatory Care Lecturer at Bahia (ADAB), in $2012(n=96)$

\begin{tabular}{|c|c|c|}
\hline VARIABLES & $\mathbf{N}$ & $\%$ \\
\hline \multicolumn{3}{|l|}{ GendeR } \\
\hline Female & 89 & 92,7 \\
\hline \multicolumn{3}{|l|}{ AGE } \\
\hline Teenager & Ol & $\mathrm{Ol}, \mathrm{O}$ \\
\hline Young Adult & $\mathrm{O} 3$ & 03,1 \\
\hline Adult & 66 & 68,8 \\
\hline Elderly & 26 & 27,1 \\
\hline \multicolumn{3}{|l|}{ ETHNIC GROUP } \\
\hline Caucasian & 10 & 10,4 \\
\hline Indian & $\mathrm{O} 3$ & O3,1 \\
\hline Black & 37 & 38,5 \\
\hline African descent & 46 & 47,9 \\
\hline \multicolumn{3}{|l|}{ SOCIAL CLASS (ABEP) } \\
\hline Al (average family income $=\mathrm{R} \$ 9,733.00$ ) & $\mathrm{O} 3$ & 03,1 \\
\hline A2 (average family income $=\mathrm{R} \$ 6,564.00$ ) & $\mathrm{O} 2$ & 02,1 \\
\hline $\mathrm{Bl}$ (average family income $=\mathrm{R} \$ 3,479.00$ ) & $\mathrm{O} 3$ & 03,1 \\
\hline $\mathrm{B} 2$ (average family income $=\mathrm{R} \$ 2, \mathrm{O} 13.00$ ) & 17 & 17,7 \\
\hline $\mathrm{Cl}$ (average family income $=\mathrm{R} \$ 1,195.00$ ) & 24 & 25,0 \\
\hline C2 (average family income = R \$726.00) & 37 & 38,5 \\
\hline $\mathrm{D}$ (average family income $=\mathrm{R} \$ 485.00$ ) & 10 & 10,4 \\
\hline \multicolumn{3}{|l|}{ SCHOOLING } \\
\hline Illiterate & 14 & 14,6 \\
\hline Primary School & 20 & 20,8 \\
\hline Middle School & 19 & 19,8 \\
\hline Secondary Scholl & 33 & 34,4 \\
\hline High Education & 10 & 10,4 \\
\hline \multicolumn{3}{|l|}{ BODY MASS INDEX } \\
\hline Underweight & O9 & 09,4 \\
\hline Normal Weight & 25 & 26,0 \\
\hline Overweight & 31 & 32,2 \\
\hline Class I Obesity & 22 & 22,9 \\
\hline Class II Obesity & 08 & 08,3 \\
\hline Class III Obesity & $\mathrm{Ol}$ & 01,0 \\
\hline
\end{tabular}

Source: Research Protocol. 
It was observed that $90.6 \%$ of patients with RA report pain, the most affected sites were the upper limbs $(52.1 \%)$, corresponding with daily frequency $(44.8 \%)$.
The most common type of pain was nociceptive (40.6\%), of high intensity (80.2\%) and high level of disease activity $(67.7 \%)$ was most frequently reported (Table 2).

Table 2. Clinical characteristics of pain in patients with RA users ADAB-2012 $(n=96)$.

\begin{tabular}{|c|c|c|}
\hline VARIABLES & $\mathrm{N}$ & $\%$ \\
\hline \multicolumn{3}{|l|}{ SYMPTOMS } \\
\hline Yes & 87 & 90,6 \\
\hline \multicolumn{3}{|l|}{ AFFECTED MEMBER } \\
\hline MMSS & 50 & 52,1 \\
\hline MMII & 45 & 46,9 \\
\hline \multicolumn{3}{|l|}{ FREQUENCY } \\
\hline No pain & ०9 & 09,4 \\
\hline Every day & 43 & 44,8 \\
\hline Almost every day & 22 & 22,9 \\
\hline Few days a week & 12 & 12,5 \\
\hline Few times a week & 10 & 10,4 \\
\hline \multicolumn{3}{|l|}{ Pain Classification } \\
\hline Neuropathic & 18 & 18,8 \\
\hline Nociceptive & 39 & 40,6 \\
\hline Both & 38 & 39,6 \\
\hline \multicolumn{3}{|l|}{ PAIN INTENSITY } \\
\hline Light & O5 & O5,2 \\
\hline Moderate & 14 & 14,6 \\
\hline Intense & 77 & 80,2 \\
\hline \multicolumn{3}{|l|}{ LDA* } \\
\hline Remission & $\mathrm{OO}$ & - \\
\hline Low Activity & 00 & - \\
\hline Moderate activity & 31 & 32,3 \\
\hline High activity & 65 & 67,7 \\
\hline
\end{tabular}

* LDA - Level of Disease Activity. Source: Research Protocol

Besides the stratified analysis for pain intensity, the median-VAS-D (0-10) was calculated and the central tendency was found for this distribution of 9.00
(8.00, 10.00), which indicates severe intensity of pain. Among the 28 joints used in DAS28, the median of swollen joints was $3.50(0.00,22.00)$ and sore joints 
was $13.50(4.00,24.75)$. In the present study, a median of $30.00 \mathrm{VHS} \mathrm{mm/h}(46.00,20.00)$ was found.

None of the participants were in remission or mild disease activity, $32.3 \%$ were included as moderate disease activity and $67.7 \%$ were included as high disease activity, with an average of $5.85 \pm 1.48$, according to the calculation of DAS28.
According to the descriptive analysis of the SF-36, the aspects that showed the greater heterogeneity in scores of QOL were physical and emotional, noting that the field with the lowest score was the physical aspect and the area with the highest score was the mental health (Table 3).

Table 3. Association of the SF-36 and HAQ with the level of disease activity in RA patients, Salvador, $2012(n=96)$

\begin{tabular}{|c|c|c|c|c|c|}
\hline \multirow{3}{*}{ DOMAINS OF QOL } & \multicolumn{5}{|c|}{ LEVEL OF DISEASE ACTIVITY } \\
\hline & \multicolumn{2}{|c|}{ MOderate } & \multicolumn{2}{|c|}{ HIGH } & \multirow[b]{2}{*}{$\mathbf{P}$} \\
\hline & AVERAGE & DP & AVERAGE & DP & \\
\hline FUNCTIONAL CAPACITY & 55,1 & 25,54 & 36,4 & 19,1 & 0,000* \\
\hline PHYSICAL APPEARANCE & 60,0 & 39,1 & 29,3 & 36,0 & $0,001^{*}$ \\
\hline PAIN & 50,3 & 14,7 & 54,4 & 14,7 & 0,328 \\
\hline VITALITY & 57,3 & 18,6 & 53,0 & 19,0 & 0,171 \\
\hline General Health & 51,1 & 16,5 & 54,6 & 16,3 & 0,552 \\
\hline SOCIAL ASPECT & 50,0 & 15,7 & 46,2 & 18,8 & 0,633 \\
\hline EMOTIONAL ASPECT & 66,6 & 43,7 & 55,5 & 37,8 & 0,275 \\
\hline Mental Health & 69,6 & 19,4 & 61,0 & 21,1 & 0,151 \\
\hline FUnCtIONAL CAPACITY (HAQ SCORE) & 0,6 & 0,5 & 1,15 & 0,6 & $0,003^{*}$ \\
\hline
\end{tabular}

* $p>0.001$ by One - way ANOVA.

The comparison analysis of $\mathrm{QOL}$ among the various levels of disease activity showed significant differences in average scores, negatively associated with the SF36 results, i.e. the lower the level o disease activity, the greater the average scored for QOL, especially related to functional capacity $(\mathrm{p}=0.001)$ and physical appearance $(p=0.001)$. Unlike, the evaluation using $\mathrm{HAQ}$, showed a higher functional capacity average levels with high level of disease activity $(p=0.003$; Table 3). The relation evaluation between other domains of the SF-36 and the level of disease activity demonstrated no statistically significant difference.

The comparison between the intensity of pain and the level of disease activity revealed a direct relation between these variables. It was observed that when the level of disease activity was higher, a higher pain intensity was also reported.

There was no association between the body areas (upper and lower limbs) most affected by the perception of pain and the level of disease activity $(p=0.340)$. Nociceptive pain was more common in people reporting a moderate level of disease activity and patients with high levels of disease activity more often associated this with concomitant nociceptive and neuropathic pain, however this demonstrated no statistical significance (Table 4). 
Table 4. Association between level of disease activity and type of pain in patients with RA users ADAB in 2012 ( $n=96$ )

\begin{tabular}{|c|c|c|c|}
\hline LEVEL OF DiSEASE ACtIVITY & $\begin{array}{c}\text { NEUROPATHIC } \\
\text { N (\%) }\end{array}$ & $\begin{array}{c}\text { Nociceptive } \\
\text { N (\%) }\end{array}$ & $\begin{array}{l}\text { Вотн } \\
\text { N (\%) }\end{array}$ \\
\hline REMISSION & $O(-)$ & $O(-)$ & $O(-)$ \\
\hline LOW ACTIVITY & $O(-)$ & $\mathrm{Ol}(100,0)$ & $O(-)$ \\
\hline MODERATE ACTIVITY & O4 $(13,3)$ & $16(053,3)$ & $10(33,3)$ \\
\hline НIGH ACTIVITY & $14(24,5)$ & $23(035,4)$ & $28(43,1)$ \\
\hline
\end{tabular}

${ }^{*}$ Chi-square test, $p=0.380$.

\section{DISCUSSION}

This study aimed to evaluate the impact of different levels of disease activity in the pain profile and quality of life in patients with rheumatoid arthritis. The main findings demonstrated that the majority of the participants in this study presented severe and nociceptive pain on a daily basis, with the level of disease activity ranging from moderate to high. This study did not report of any cases in the remissive period.

The finding that middle-aged women seem to be more affected by RA is consistent with the literature. $(1,13,14)$ Although many studies report the predominance of Caucasians, ${ }^{(15)}$ in the present sample, African descent individuals were predominant. This finding is related to the sociodemographic characteristics of Bahia ${ }^{(16)}$ and is according to the consent of the Brazilian Society of Rheumatology(1) demonstrating that RA occurs in all ethnic groups.

The incidence of RA has not shown association with socioeconomic status and education level. However, in the present sample evaluated in this study, there was a predominance of individuals with high level of education and the middle socioeconomic class. This finding may be related to the fact that more formally educated individuals seek more health services, and that RA cases affecting the lower socioeconomic classes may be underreported due to mobility and transportation difficulties. ${ }^{(1)}$

Excessive body weight has been implicated as a factor accelerating the degenerative articular process in RA patients. Although there was no association between body weight and level of disease activity level, the present study demonstrated that excess abdominal fat is directly linked to inflammation, which may explain the prevalence of metabolic syndrome in patients with RA. ${ }^{(17)}$

The painful profile of RA patients showed that severe and nociceptive pain was present daily, affecting mainly the upper limbs, with no association between the level of disease activity and pain intensity. It is currently believed that a repetitive stimulus, bacterial or non-bacterial, and non-specific stimulus can cause tissue injury in genetically predisposed individuals with activation of antigen presenting cells (APC) and T lymphocytes, specifically $C_{4}$, known as helper cells. When these T lymphocytes are activated, produce cytokines that activate macrophages and other cells from the articular synovial membrane, initiating a cascade reaction of pro-inflammatory cytokines, especially TNF- $\alpha$, that promote stasis and leukocyte migration to microcirculatory vessels and cell migration. The role of prostaglandins, particularly PGE2, is indisputable, causing vasodilation, increased permeability and pain. ${ }^{(18)}$

Despite the fact that RA patients were undergoing treatment with drugs that modify the disease course (DMARDs) and anti-inflammatory drugs (NSAIDs), a common current treatment combination, the majority of the patients presented moderate and high level of disease activity.(1)

It was also found that the greater the intensity of the pain as associated with a greater the level of disease 
activity. This finding was expected, because the marker for inflammatory activity (VHS) tested in this sample was consistently high through the study, evidencing the degree of synovial inflammation.

The mixed characteristics of joint pain indicates simultaneous nerve lesion (lesion or dysfunction of the nervous structures of central or peripheral system - burning, prickling, tingling) and adjacent tissue (tissue damage demonstrable - osteoarthritis, RA, fracture and muscular stiffness in nonspecific low back pain) as is observed in the genesis of cancer pain, sciatic and carpal tunnel syndrome. Regarding RA, edema, characterized by excess fluid in the interstitial compartment causes inflammation and compression of adjacent structures, resulting in the pain sensation. ${ }^{(1)}$

Alterations in different dimensions evaluated by SF-36 were observed, with the lowest values related to physical aspects and functional capacity. This observation is justified by the presence of chronic disease associated with diminishing quality of life in this population, especially in carrying out activities of daily living, as these patients present deformity, pain, and joint inflammation, resulting in articular edema and restriction of movement. Similar studies have found that the dimensions of the SF-36 in patients with RA have major impacts on the physical and mental health of the individual. ${ }^{(19)}$

However, previous studies have shown that variables related to disease activity are major determinants of physical disability, but not necessarily mental health. An explanation to this mechanism is that disease activity is closely related with the degree of damage, pain, swelling and stiffness of the joints. Furthermore, disease activity is associated with rapid loss of ability to work, premature mortality, and reduced quality of life. ${ }^{(20)}$

In the current study, the level of disease activity was significantly correlated with HAQ demonstrating that disease activity is an important determinant of functional disability in RA patients. The level of disease activity was also significantly correlated with functional capacity and physical aspect of these patients, in accordance with other studies. The patients with RA that presented the higher disease activity scores, expressed by the DAS-28, also reported a worsening in physical function, and was related with more frequent comorbidities and a decline in overall health measured by the SF-36. ${ }^{(21,22)}$

This study had limitations inherent to any crosssectional model and also in categorizing the most affected body sites, such as arms and legs, due to the fact that the DAS28 does not include ankles and feet. There are prospects for continuing this research in order to develop specific protocols for the treatments of each type of pain.

In conclusion, the type of pain that most affects the RA patients is nociceptive, despite the fact that many individuals present characteristics of mixed pain (nociceptive and neuropathic). The level of disease activity strongly impacts the functionality and quality of life of these individuals, mainly affecting their physical features and functional capacity. Patients with rheumatoid arthritis who presented high level of disease activity reported more pain perception, specifically in relation to severe intensity of pain, and report lower of quality of life scores. There was no impact between level of disease activity and type of pain in this sample.

\section{References}

1. Mota LMH, Cruz BA, Brenol CV, Pereira IA, Resende-Fronza LS, Bertolo MB et al. Brasilian Society of Rheumatology Consensus for the treatment of rheumatoid arthritis. Rev bras reumatol. 2012;52(2):135-174.

2. Costa AFC, Brasil MAA, Papi JA, Azevedo MNL. Depressão, ansiedade e atividade de doença na artrite reumatoide. Rev. bras. reumatol. 2008; 48(1):7-11.

\section{Corbacho MI, Dapueto JJ. Assessing the} functional status and quality of life of patients with rheumatoid arthritis. Rev bras reumatol. 2010;50(1):31-43.

4. Laar MV, Pergolizzi Júnior JV, Mellinghoff HU, Merchante IM, Nalamachu S, O'Brien J. et al. Pain Treatment in Arthritis-Related Pain: Beyond NSAIDs. Open Rheumatol J. 2012; 6: 32O-330.

5. Treede RD, Jensen TS, Campbell JN, Cruccu G, Dostrovsky JO, Griffin JW et al. Neuropathic pain: redefinition and grading system for clinical and research purposes. Neurology. 2008; 70(18):1630-5. 
6. Di Costanzo L, Ayala F, Megna M, Gaudiello F, Patri A, Balato N. The risk of herpes zoster in the anti-TNF- $\alpha$ era: a case report and review of the literature. J Dermatol Case Rep. 2013; 7(1):1-4.

7. Deepak P, Stobaugh DJ, Sherid M, Sifuentes H, Ehrenpreis ED. Neurological events with tumour necrosis factor alpha inhibitors reported to the Food and Drug Administration Adverse Event Reporting System. Aliment Pharmacol Ther. 2013;38(4):388-96.

8. Grear BJ et al. Charcot arthropathy of the foot and ankle associated with rheumatoid arthritis. Arthritis Rheum. 2012;64(2):371-9.

9. Wartolowska K, Hough MG, Jenkinson M, Andersson J, Wordsworth BP, Tracey I. Structural changes of the brain in rheumatoid arthritis. Arthritis Rheum. 2012;64(2):371-9.

1O. Garip Y, Eser F, Aktekin LA, Bodur H. Fatigue in rheumatoid arthritis: association with severity of pain, disease activity and functional status. Acta Reumatol Port. 2011;36:364-369

11. Ibn Yacoub Y, Amine B, Laatiris A, Hajjaj-Hassouni N. Health-related quality of life in Moroccan patients with rheumatoid arthritis. Clin Rheumatol 2012; 31:1471-1477.

12. Pinheiro GRC. Instrumentos de medida da atividade da artrite reumatoide: porque e como empregá-los. Rev. bras. reumatol. 2007; 47(5):362365.

13. Teixeira RCA, Gabriel Júnior A, De Martino MC, Martins LC, Lopes AC, Tufik S. Marcadores de ativação endotelial e auto-anticorpos na artrite reumatoide. Rev. bras. reumatol. São Paulo. 2007; 47(6):411-417.

14. Bertolo MB et al. Consenso brasileiro de doenças reumáticas: atualização do consenso brasileiro no diagnóstico e tratamento da artrite reumatóide. Temas reumatol. clin. 2009; 10(1):6-14.
15. Goeldner I, Skare TL, Reason ITM, Utiyama SRR. Artrite reumatóide: uma visão atual. J. bras. patol. med. lab. 2011; 47(5):495-503.

16. Sá KN Baptista AF, Matos MA, Lessa I.

Prevalência de dor crônica e fatores associados na população de Salvador, Bahia. Rev. saúde pública. Salvador. 2009; 43(4):622-630.

17. Pereira IA, Mota LMH, Cruz BA, Brenol CV, Resende-Fronza LS, Bertolo MB et al. Consenso 2012 da Sociedade Brasileira de Reumatologia sobre o manejo de comorbidades em pacientes com artrite reumatoide. Rev bras reumatol. 2012; 52(4):474-495.

18. Laurindo IMM. In: Artrite reumatóide. In: Voltarelli JC et al. Imunologia clínica na prátiva médica. São Paulo: Atheneu. 2008. p. 623-636.

19. Bazzichi L, Maser J, Piccinni A, Rucci P, Del Debbio A, Vivarelli $L$ et al. Quality of life in rheumatoid arthritis: impact of disability and lifetime depressive spectrum symptomatology. Clin Exp Rheumatol. 2005;23:783-788.

2O. West E, Jonsson SW. Health-related quality of life in rheumatoid arthritis in Northern Sweden: a comparison between patients with early RA, patients with medium-term disease and controls, using SF-36. Clin Rheumatol. 2004; 24(2):117-122.

21. Alishiri GH, Bayat N, Salimzadeh A, Salari A, Hosseini SM, Rahimzadeh S et al. Health-related quality of life and disease activity in rheumatoid arthritis. J Res Med Sci. Tehran, Iran. 2011; 16(7):897903.

22. Dadoniene J et al High work disability rate among rheumatoid arthritis patients in Lithuania. Arthritis \& Rheumatism. 2004; 51(3):433-9. 